\title{
Dos tempos e lugares do campo educacional: uma análise dos percursos de investigação em Portugal (1900-2000)*
}

José Augusto Pacheco

Universidade do Minho, Instituto de Educação e Psicologia

Este texto incide sobre os tempos e lugares do campo educacional, ${ }^{1}$ ou das ciências da educação, pretendendo-se fazer uma análise reflexiva sobre os percursos de investigação desde a sua emergência até a fase da sua maturidade e consolidação epistemológica. Os lugares estão no aparelho administrativo do Estado, sobretudo nos ministérios ligados à educação e à ciência, nas instituições de ensino superior e nas escolas dos ensinos básico e secundário. Os tempos investigativos encontram-se na encruzilhada de dúvidas, de dependências, de incertezas e de uma coragem que falta alicerçar no interior da comunidade científica comprometida com as ciências sociais e com as questões relativas ao campo educacional.

* Apresentado na $26^{\mathrm{a}}$ Reunião da ANPEd, realizada em Poços de Caldas, MG, de 5 a 8 de outubro de 2003. Foi conservada a ortografia de Portugal.

${ }^{1}$ Ao adoptarmos esta expressão, parafraseamos o título "O tempo e o lugar das ciências da educação” de Albano Estrela (1999).

\section{A designação "ciências da educação"}

A expressão "ciências da educação", para referir a designação mais utilizada de momento em Portugal, revela quer a noção de temporalidade, na medida em que surge como alternativa consolidada ao termo educação, quer uma série de equívocos, dentro dos quais se reconhece o percurso pluralista da difícil construção e implantação do conhecimento educativo. Os equívocos "resultam, por um lado, da falta de elucidação da problemática que a expressão envolve e, por outro, da sua vulgarização enquanto substituto do termo pedagogia. Por isso "[é] pertinente que se proceda a um debate que possibilite não só uma definição do corpo teórico das ciências da educação, como também a determinação do seu poder operacional em estudos científicos que tenham a educação como campo" (Estrela, 1992, p. 11).

O debate sobre a fundamentação epistemológica da pedagogia/ciências da educação/educação tem ocorrido ao mesmo tempo que se verifica a consolidação do campo da educação como ramo de conhecimento, com diferentes áreas de especialização. Qual- 
quer história das ciências da educação terá forçosamente espaço para o campo das polémicas científicas, cuja análise não se faz aqui.

No entanto, convém relembrar que "uma teoria das polémicas, preocupada tanto pela sua natureza dialógica como pelo papel histórico e epistemológico, deve analisá-las a vários níveis: desde o nível 'micro' do encadeamento sucessivo até ao nível 'macro' da sua estrutura global” (Dascal, 1999, p. 69). E mais: "o carácter discutível e quase arbitrário (por falta de um critério de base) das tentativas de classificação das ciências da educação são a melhor prova da falta de definição do seu estatuto" (Estrela, 1992, p. 13).

A consolidação do campo das ciências da educação, aliás dentro das designações que caracterizam outros campos de estudos, por exemplo, ciências da saúde, ciências do ambiente, tem sido realizada na fronteira da emergência de campos disciplinares híbridos como resposta mais a uma ordem profissional do que a uma ordem científica. Assim, as raízes da educação encontram-se tanto na origem da escola quanto na "industrialização" do acto de aprender e ensinar que seguiu o percurso da centralização administrativa, dentro daquilo a que se pode chamar a lógica de Estado (Pacheco, 2003).

O hibridismo da educação, reforçado cada vez mais por abordagens multirreferenciais, pode ser visto de perspectivas diferentes. Uma delas aponta claramente para a ausência de um estatuto próprio:

Quando se analisa o fenómeno educativo sob o ângulo de outras ciências, já constituídas (psicologia, sociologia, fisiologia, economia, história), são na verdade, os objectos da teoria e da prática dessas ciências que são detectados. Portanto, a especificidade do fenómeno educativo fica totalmente diluída, tanto ao nível da prática como ao da formulação teórica. (Estrela, 1992, p. 14)

Tais palavras expressam fielmente a dificuldade da cientificação da educação e a opção pela noção "ciências da educação", decerto para buscar um estatuto epistemológico já devidamente consolidado.
Como reconhece numa outra obra, escreve Albano Estrela (1999, p. 8):

Se a abordagem predominante tem sido, como vimos, marcada pela pluralidade fundadora das ciências da educação, ciclicamente surge a tomada de consciência de que essa pluralidade se revela insuficiente para captar a especificidade própria do campo educativo e pedagógico. Assim, estaríamos actualmente numa fase de transição que, segundo o reputado investigador norte-americano Othaniel Smith, se caracterizaria por uma "reforma sobre o modo de pensar o conhecimento pedagógico, por uma reencontrada confiança nesse conhecimento e por uma tendência para pensar mais objectivamente. [...] A constituição de saberes específicos ao campo educativo, que progressivamente se foram estruturando, em ordem a uma definição conceptual e a uma prática de investigação a eles inerente, como será o caso da Teoria e Desenvolvimento Curricular, a Avaliação Educacional, a Administração Educacional, a Didáctica, parecem confirmar a possibilidade e a legitimidade dessa abordagem, por direiro próprio feita.

Se insistirmos na proposta de uma ciência da educação, sem amarras espistemológicas às ciências auxiliares já consolidadas, a que ciência ligamos, por exemplo, os estudos curriculares? A este respeito, relata-nos Cleo Cherryholmes (1993, p. 143):

O currículo como um campo de estudo não deriva, como muitos outros campos da educação, de outras disciplinas académicas ou aplicadas. A Psicologia educacional tem raízes na Psicologia, a Filosofia da educação na Filosofia, o estudo das políticas educacionais na Ciência política e a Administração educacional nos campos aplicados da Administração pública e privada. O currículo lida com problemas que são singularmente educacionais da mesma forma que o ensino tem suas próprias tarefas especiais [...] uma tal independência é rara.

Reconhece-se, por isso, que a identidade conceptual da educação é de natureza prática, ligada aos contextos social e cultural nos quais está inserida, e que toda tentativa de encontrar a designação adequa- 
da revela diversos pontos controversos. E se ligarmos a origem do campo educativo ao âmbito departamental das universidades, então as diferentes disciplinas educativas são perspectivadas por razões que se prendem com as concepções particulares dos responsáveis académicos e não tanto com os argumentos efectivamente epistemológicos. Esta afirmação é constante nas instituições de formação que têm ciências da educação, pois nelas existem as terminologias e associações de campos temáticos como se estes fossem miméticos dos poderes e das forças instituintes dos campos de saber dentro das universidades. No caso concreto do campo educativo, ele deve ser visto como parte dos jogos de interesse que definem o trabalho académico e os processos de legitimação das diversas correntes científicas (Lerbert, 1996; Wulf, 1995).

A este propósito, Miguel Zabalza (1992, p. 138) argumenta que "todos sabemos que as disciplinas universitárias figuram no universo científico por diversas razões (razões históricas, por conveniência da administração, por motivos de emprego, por circunstâncias conjunturais, por pressões dos grupos profissionais etc.). As fronteiras entre as disciplinas são cada vez mais difusas".

Embora se reconheça cada vez mais a dispersão disciplinar, sobretudo nos cursos de pós-graduação, o facto é que esta flexibilidade é determinada pela política universitária e pela função que cada disciplina desempenha: "a função de disciplinar as mentes e de canalizar a energia utilizada na actividade intelectual e de investigação. Tem, contudo, que haver algum grau de consenso quanto à validade das linhas de demarcação, se é que estas hão-de servir para alguma coisa" (Comissão Gulbenkian, 1996, p. 132).

Apesar da existência de uma lógica organizacional na definição dos departamentos e grupos disciplinares, que se explica pelas dinâmicas e processos variáveis com a experiência e vivências dos docentes que, congregados em domínios de conhecimentos particulares, vão construindo entre si laços de pertença a uma organização, o certo é que a educação tem vindo a ser reconhecida como domínio de co-

nhecimento mais por factores institucionais do que pela assunção de saberes justificados por uma lógica epistemológica. Daí que o conceito de comunidade científica, por mais complexo que seja, tal como o entenderam Polnayi, Kuhn e Merton (cf. Jesuíno, 1995a), pode ser analisado na acepção mais restrita ao nível disciplinar.

Temos então as comunidades científicas enquanto grupos de cientistas trabalhando num determinado domínio disciplinar, ou ainda as comunidades científicas "nacionais", correspondendo ao conjunto de cientistas trabalhando num determinado país. Estes dois subconjuntos são ainda susceptíveis dos mais diversos cruzamentos. (Jesuíno, 1995a, p. 1)

Nos resultados sobre a comunidade científica portuguesa, no âmbito das diferentes ciências (exactas, naturais, da engenharia, da saúde, da agricultura, sociais) é comprovada a

[...] hipótese de que a comunidade científica, a uma análi-
se mais fina, tende a apresentar-se não como grupo social
homogéneo, mas antes como uma constelação de discipli-
nas com fronteiras difusas e provavelmente escassa co-
municação interdisciplinar, embora suficiente, na hipóte-
se de Crane e Mulkay, para gerar novas áreas de investiga-
ção. Os resultados obtidos quanto a este último aspecto
permitem confirmar que a comunicação se processa so-
bretudo no interior dos grandes campos disciplinares, sen-
do muito escassa a comunicação entre eles. (Jesuíno,
$1995 b$, p. 185)

\section{O campo educacional no contexto das ciências sociais}

Sendo a ciência um diálogo constante com a natureza, o seu papel, segundo Abraham Moles (1981, p. 33), não é o de prever a marcha do universo na sua minúcia, mas o de "construir um modelo inteligível que sirva à apreensão da natureza pelo homem" e que deve ser perspectivado quer pelo "fim das certezas" 
(Prigogine, 1996), ${ }^{2}$ quer pela descontinuidade e multiplicidade da construção da realidade, ${ }^{3}$ quer ainda pelos paradigmas dominantes, aceitando-se que "um paradigma torna-se o modo de ver e descrever uma realidade e não é apenas uma maneira de ver essa mesma realidade" (Formosinho, 1988, p. 12).

No contexto da dualidade do pensamento ocidental, o discurso científico divide-se entre a realidade das ciências naturais, relacionadas com a objectividade através dos princípios do racionalismo de Descartes e do empirismo de Locke, e a realidade das ciências sociais, identificadas pelo significado subjectivo e compreensão dos actores de Weber. Tratase da relação explicação/compreensão que tem marcado o confronto epistemológico, como reconhece Boaventura Santos (1993, p. 55): “A questão de saber se o estatuto da cientificidade ou a forma lógica das ciências sociais é igual ou diferente do das ciências naturais é uma das mais discutidas e das menos resolvidas em todo o discurso epistemológico".

Torna-se uma tarefa impossível, porque intrinsecamente contraditória, a procura de ideias universais alicerçadas numa ordem racional da realidade que permita a resolução de problemas mediante a enunciação de regularidades empíricas. Mais difícil ainda quando se reconhece que as fronteiras entre o objectivo e o subjectivo são ténues: "se o que se entende por objectividade é termos estudiosos perfeitamente distanciados, entregues à tarefa de produzir um mundo social que lhes é de todo exterior e alheio, então não acreditamos que um tal fenómeno possa existir" (Comissão Gulbenkian, 1996, p. 127-128).

\footnotetext{
${ }^{2}$ Mesmo os filósofos, diz-nos Anthony Giddens (1996,
} p. 28), "que defendem mais fielmente as reivindicações de certeza da ciência, tais como Karl Popper, reconhecem que, como ele o exprime, 'toda a ciência assenta em areia movediça'. Na ciência, nada é certo, e nada pode ser provado, mesmo se o esforço científico nos oferece a informação mais fiável sobre o mundo a que podemos aspirar".

${ }^{3}$ Para Jean Hamburger (1988, p. 9-10), “o que nós chamamos realidade não é mais do que uma síntese humana aproximativa, construída a partir de observações diversas e de olhares descontínuos".
O objecto específico das ciências sociais é cultural e socialmente produzido, já que é constituído pelos "seres humanos, agentes socialmente competentes, que interpretam o mundo que os rodeia para melhor agirem nele e sobre ele" (Santos, 1993, p. 63), a quem a "ciência empírica não está apta a ensinar aquilo que 'deve', mas sim e apenas o que 'pode' e em certas circunstâncias - o que 'quer' fazer" (Weber, 1977, p. 17).

Com efeito, Max Weber (1977) enquadra as ciências sociais nos campos das ciências da cultura ${ }^{4}$ e da ciência da crença, marcada pelo lado pessoal da crença e pelas ideias de valor: "a validade objectiva de todo o saber empírico baseia-se única e exclusivamente no facto de a realidade dada se ordenar segundo categorias subjectivas, no sentido específico de constituírem a pressuposição do nosso conhecimento e de se ligarem à pressuposição do valor da verdade que só o saber empírico nos pode proporcionar" (p. 108).

Esta crença, admitida por Max Weber, na convivência entre os saberes objectivo e subjectivo, é questionada por Boaventura Santos (1993), não só ao reconhecer que "as ciências sociais são epistemologicamente prioritárias em relação às ciências naturais" (p. 75), bem como ao enunciar o seguinte princípio: "as ciências naturais são ainda diferentes das ciências sociais, mas aproximam-se cada vez mais destas e é previsível que, em futuro não muito distante, se dissolvam nelas" (p. 56).

O que justifica esta convicção, pois nas ciências sociais o interesse reside na configuração do real a partir da subjectivação, é a concepção de uma ciência pósmoderna ${ }^{5}$ fundamentada na noção de círculo herme-

${ }^{4}$ Onde "o conhecimento do geral, a formação de conceitos genéricos e abstractos, o conhecimento de regularidades e a tentativa de formulação de relações 'regulares', não possuem uma justificação científica”. Cf. Max Weber (1977, p. 58).

${ }^{5}$ Para Boaventura Santos (1993, p. 9), “a época em que vivemos deve ser considerada uma época de transição entre o paradigma da ciência moderna e um novo paradigma, de cuja emergência se vão acumulando os sinais, e a que, à falta de melhor designação, chamo ciência pós-moderna". 
nêutico, e que se constitui num recurso de compreender a ciência enquanto prática social de conhecimento.

A reflexão hermenêutica, sustenta Boaventura Santos (1993), para além de "tornar compreensível o que as ciências sociais são na sociedade e o que elas dizem sobre a sociedade" (p. 13), implica um discurso racional orientado pelo desejo de diálogo com o objecto da reflexão e tem por objectivo principal "democratizar e aprofundar a sabedoria prática, a phronesis aristotélica, o hábito de decidir bem" (p. 31).

Tal saber prático, que dá sentido e orientação à existência e cria o hábito de decidir bem, parte do pressuposto da valorização do senso comum, assim historicamente analisado por Boaventura Santos (1993, p. 39-40):

A valorização filosófica do senso comum esteve, pois, ligada ao projecto político de ascensão ao poder da burguesia, pelo que não surpreende que, uma vez ganho o poder, o conceito filosófico de senso comum tenha sido correspondentemente desvalorizado como significando um conhecimento superficial e ilusório. É contra ele que as ciências sociais nascem no séc. XIX. Mas ao contrário das ciências naturais, que sempre recusaram frontalmente o senso comum sobre a natureza, as ciências sociais têm tido com ele uma relação muito complexa e ambígua.

O pressuposto de que o saber empírico é o mais adequado para analisar a realidade é evidentemente secundário quando estamos perante um objecto que só se torna inteligível se for compreendido na sua significação particular e no processo contínuo de produção de ideias, historicamente consideradas as mais válidas e adequadas para compreender uma dada realidade.

Neste sentido, sublinhamos a certeza de Max Weber (1977, p. 50):

[...] não há qualquer dúvida de que o ponto de partida do interesse pelas ciências sociais reside na configuraçãoreal, istoé, singular, da vida sociocultural que nos rodeia, quando queremos apreendê-la no seu contexto universal, nem por isso menos singular, e no seu desenvolvimento a partir de outros estados socioculturais, naturalmente singulares também.
As noções de teoria e prática são analisadas a partir não só de uma multiplicidade de significados, bem como de modos particulares de legitimação científica. Considerando que a educação não pode ter como base de fundamentação epistemológica nem o modelo das ciências naturais - rejeitando-se desta maneira que o acto educativo seja susceptível de verificação e comprovação empírica -, nem a procura de uma normatividade, cujos princípios sejam construídos na procura de uma realidade única, a definição da teoria e da prática educativas comporta obrigatoriamente a filosofia das ciências sociais.

$\mathrm{O}$ conceito weberiano de ciências sociais, como vimos, reforça a singularidade da realidade e torna inoperante o esforço de elaborar teorias científicas, correspondentes a ideias, na linha do que é proposto por Khun e Popper, que expressam uma série de declarações empiricamente comprováveis. ${ }^{6}$ Porém, a longa evolução das ciências mostra-nos que "as certezas absolutas, totais e definidas, estão excluídas do mundo da ciência" (Delattre, 1992, p. 273).

Reconheçamos com Mário Bunge (1980, p. 160) que "nas ciências sociais há uma tendência de dignificar com o nome de teoria qualquer amontoado de opiniões, por desconexas e infundadas que sejam. Quase sempre se trata meramente de quadros teóricos ou de doutrinas". Neste terreno das ciências sociais, o termo teoria aplica-se "às concepções ou explicações que os sujeitos têm dos fenómenos e realidades, relacionando-se com os conceitos de crença, pensamento e saberes dos sujeitos" (Gimeno, 1998, p. 31), não podendo desprender-se das práticas so-

${ }^{6}$ Nesta perspectiva experimental, segundo Anatole Abragman (1988, p. 25), “a teoria consiste em pôr uma ordem coerente num conjunto de ideias que foram ou serão confrontadas na experiência”. No entanto, como refere P. Delattre (1992, p. 268), o estudo das várias disciplinas evidencia "as imensas dificuldades encontradas para alcançar princípios explicativos suficientemente precisos de um nível de generalidade adequado, permitindo elaborar esquemas teóricos convincentes, isto é, que dêem respostas satisfatórias às questões que se colocam”. 
ciais, aliás como propõem diversos pensadores como Althusser, Derrida e Foucault.

Tal relação permite que os investigadores de diferentes áreas tenham concepções tão diversas no que diz respeito ao reconhecimento do estatuto científico do seu campo disciplinar. Deste modo, e reportandonos novamente ao resultados sobre a comunidade científica portuguesa,

[...] os inquiridos das disciplinas das ciências naturais e exactas são aqueles que reivindicam maior grau de cientificidade para o seu campo disciplinar. Os inquiridos das áreas das ciências agrícolas, da saúde e das engenharias apresentam algum criticismo relativamente à integração do seu campo disciplinar no saber científico, ao mesmo tempo que também são críticos aos outros campos disciplinares. As ciências sociais concedem mais facilmente um estatuto científico aos outros campos do que a si próprias, mas reivindicam para si um estatuto mais científico do que aquele que os outros lhe concedem. (Vala \& Amâncio, 1995, p. 99)

Voltando ao conceito de teoria, que significados adquire a teoria em educação? ${ }^{7}$

É evidente que não aplicamos à educação a noção de teoria tal como é definida no contexto da produção das grandes teorias ou das denominadas teorias científicas, pois estes significados, baseados no método experimental, não são coerentes com a educação. Qualquer definição passa, assim, ora pela perspectiva de Stephen Ball (1995) - a teoria como veículo para pensar de outro modo (thinking otherwise) -, ora pela noção de Gary Thomas (1997, p. 101): “a teoria é reflexão e pensamento" e que abarca a noção de reflexão estruturada de Carr, a acção racional de Hirst e a teorização prática de McIntyre.

Partindo do sentido fundamental em que a reflexividade é uma característica que define toda a acção humana, Anthony Giddens (1996, p. 28) argumenta que

${ }^{7}$ Para George Beauchamp (1961, p. 18), “o termo teoria é o que nós utilizamos frequentemente na literatura educacional, mas também muito raramente é definida". "o conhecimento reflexivo, de que as ciências sociais são a versão formalizada (um género específico de conhecimento pericial), é verdadeiramente fundamental para a reflexividade de modernidade como um todo".

Neste sentido, a teoria em educação não tem a conotação científica que é dada pela comprovação empírica, na medida em que "a educação não se interpreta como um fenómeno natural mas como uma prática social situada na história e imersa numa cultura, vulnerável às deformações ideológicas, às pressões institucionais e demais formas de limitação educativa" (Carr, 1985, p. 155). Pelo contrário, a teoria adquire o sentido da interpretação e organização sistemática de práticas educativas.

Porém, como refere Silva (2000, p. 9-10), na perspectiva pós-estruturalista

[...] a teoria não se limitaria, pois, a descobrir, a descrever, a explicar a realidade: a teoria estaria irremediavelmente implicada na sua produção. Ao descrever um "objecto", a teoria, de certo modo inventa-o. O objecto, que a teoria supostamente descreve, é efectivamente um produto de sua criação. Nessa direcção, faria mais sentido falar não em teorias, mas em discursos ou textos [...] uma teoria supostamente descobre e descreve um objecto que tem uma existência independente relativamente à teoria. Um discurso, pelo contrário, produz o seu próprio objecto: a existência do objecto é inseparável da trama linguística que supostamente o descreve.

Baseando-nos em Gimeno (1998, p. 29), “denominamos como 'teoria' a sistematização organizada de conhecimentos - corpus teórico - que constituem um campo disciplinar determinado, seja considerado ou não como ciência". Concomitantemente, "partiremos, pois, da acepção de prática educativa como acção orientada, com sentido, pelo que o sujeito tem um papel fundamental como agente, ainda que inserido na estrutura social" (p. 31).

$\mathrm{Na}$ representação gráfica da relação entre teoria e prática definem-se, geralmente, dois extremos opostos: a teoria, no lado da máxima abstracção; a prática, no lado da mínima acção (Figura1): 
Figura 1 - Relação teoria/prática

\begin{tabular}{l}
\multicolumn{1}{c|}{$\begin{array}{l}\text { Teoria como } \\
\text { ideia ou hipótese }\end{array}$} \\
\hline $\begin{array}{l}\text { Teoria como declarações } \\
\text { expressas formalmente }\end{array}$ \\
\hline
\end{tabular}

Fonte: Thomas, 1997.

Neste caso, sobretudo com a afirmação dos princípios do pensamento racionalista, aceitar-se-ia que a teoria cumpre a função de orientação da prática, podendo melhorá-la significativamente. No contexto educativo, seria sustentar que "a prática é o que fazem os professores, a teoria é o que fazem os filósofos, pensadores e investigares da educação" (Gimeno, 1998, p. 25).

Esta relação teoria/prática é indissociável e não representa mais do que as duas faces de uma mesma realidade: por um lado, a face da possibilidade e, por outro, a face da realidade. Só através de uma perspectiva pragmática, como propõe James Macdonald (1995, p. 176-177), é que poderemos entender totalmente esta relação não dicotómica, mas de interdependência:

A teoria enquanto reflexão sistemática e formal é uma abstracção que se baseia no pensamento comum em qualquer campo da actividade humana. A prática resulta da acção constante que acompanha a reflexão quotidiana. Quer a teoria, quer a prática existem em determinadas formas sociais e culturais. Todas as ciências humanas começam por reportar-se a uma experiência vivida, pelo menos implícita, e proporcionam uma determinada leitura dessa mesma realidade. Os dados das ciências sociais configuram uma base para a imaginação da nossa experiência da vida do mundo.

Nesta perspectiva, a relação teoria/prática não pode ser analisada à luz dos princípios do positivismo: "A abordagem positivista do problema da teoria e da prática baseia-se na convicção de que é possível pro- duzir explicações científicas das situações educacionais e de modo que estas possam ser utilizadas para tomar decisões objectivas no que diz respeito às linhas de acção" (Carr \& Kemmis, 1988, p. 91). Esta impossibilidade reside basicamente na estrutura da acção que, por mais orientação teórica que a determine, é sempre pessoal e dominada por três componentes fundamentais ${ }^{8}$ - a dinâmica, correspondente aos motivos e às intenções; ${ }^{9}$ a cognitiva, respeitante à consciência e ao conhecimento pessoal; a prática, abrangente da experiência do saber-fazer pessoal - que integram os sujeitos nos planos cultural e social (Figura 2):

Figura 2 - As dimensões das acções

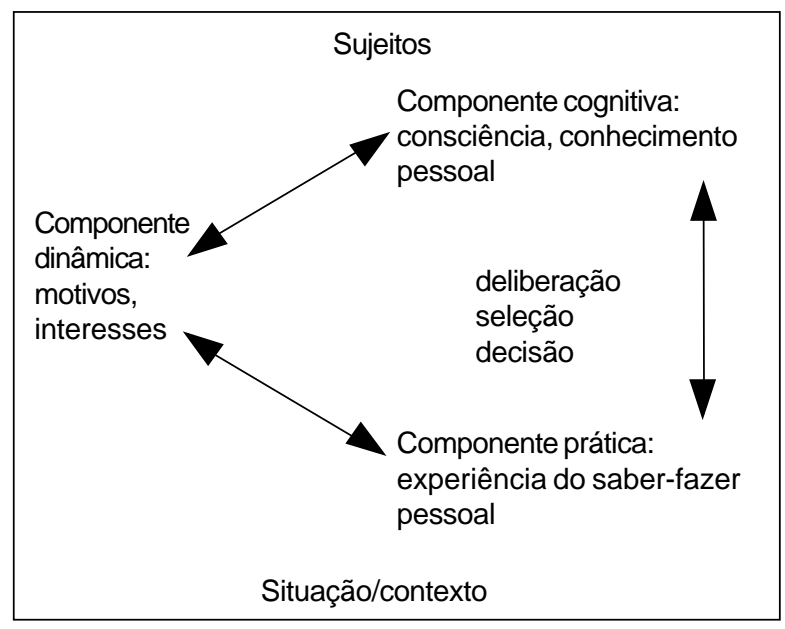

Fonte: Gimeno, 1998

${ }^{8}$ As dimensões das acções são justificadas por José Gimeno (1998, p. 71-72) deste modo: “o mundo da acção pedagógica não é o da técnica (techne) em que as regras fixas regulam acções para atingir metas. Tampouco é o de um mundo determinado totalmente por leis e estruturas externas. Pelo contrário, é o da práxis aristotélica descoberta por sujeitos, pelo que o raciocínio prático dirige-se à acção moralmente informada acerca do que se torna conveniente em cada momento. Trata-se de um saber que não é constituído por regras, mas por princípios aplicados com sabedoria".

${ }^{9}$ É neste enquadramento que James Macdonald (1995, p. 176) propõe que "a problemática da teoria-prática deve ser perspectivada num contexto alargado, cujo processo Paul Ricouer e Hans-George Gadamer chamam de círculo hermenêutico". 


\section{Os lugares do campo educacional}

Os lugares do campo educacional estão ligados ao aparelho administrativo do Estado, sobretudo nos ministérios ligados à educação e à ciência, nas instituições de ensino superior e nas escolas dos ensinos básico e secundário. Pode-se, inclusive, afirmar que o campo educacional, em Portugal, foi construído primeiramente em torno da formação inicial de professores, e que agora se volta também para a formação inicial de educadores e formadores e para a formação contínua de educadores, professores e formadores.

A institucionalização da formação inicial de professores em Portugal começou em 1901, com a reorganização do curso de letras da Universidade de Lisboa, ${ }^{10}$ com o propósito de conferir uma habilitação através de uma formação que mantenha "um fim científico, isento da acção perturbadora ou nociva proveniente de qualquer empirismo prático". ${ }^{11}$ A criação das escolas superiores, em 1911, das Universidades de Coimbra e Lisboa, consolida a "alta cultura pedagógica", ${ }^{12}$ acrescentando-se, em 1930, a prática pedagógica através da realização de um estágio de dois anos num liceu escolhido pela administração central.

Depois de um longo período de ideologização da formação de professores, nos anos dourados do Estado Novo, os anos de 1970 reforçam a universitarização da formação e profissionalização de professores, facto que faz surgir com alguma pujança disciplinas ligadas ao campo educacional. Embora se possa discutir até que ponto as universidades devem ser, ou não, lugares de formação profissional, o facto é que "a universitarização de uma formação profissional é, à distância e vista do exterior, necessariamente entendida como a assunção, mesmo tácita que seja, de que há um corpo de conhecimentos científicos acumulados e disponíveis de que a universidade

${ }^{10}$ A reorganização do curso de ciências fez-se em 1902.

${ }^{11}$ Cf. decreto de 24 de dezembro de 1901. Tais escolas serão extintas em 1930.

${ }^{12}$ Cf. decreto de 29 de maio de 1911. deteria o património e que poderiam ser investidos na preparação para a profissão em referência" (Esteves, 2002, p. 40).

$\mathrm{O}$ reforço desta tendência verifica-se, nos finais dos anos de $1980,{ }^{13}$ com a publicação por parte da administração central do ordenamento jurídico da formação inicial de professores, estipulando-se, dentro de percentagens bem definidas, como obrigatória a formação científica no domínio pedagógico-didáctico, para além da formação pessoal, da formação científica nas ciências da especialidade de formação do professor e da prática pedagógica (Pacheco, 1995).

Todavia, trata-se de uma declaração de jure, pois, na realidade, permanecem as realidades de formação impostas pelas práticas de cada organização. Digamos que, na actualidade, mesmo passados 14 anos, a formação inicial de professores é mais determinada pelas práticas organizativas das instituições de ensino superior do que pelas políticas de formação oriundas da administração central e pelas orientações das organizações multilaterais.

Os fortes ventos políticos, sobretudo ligados às políticas de formação profissional, trazem outros termos que poderão impor novas regras, sabendo-se que o campo educacional é visto de forma culpabilizante, dado que será o responsável pela degradação das aprendizagens e pela falta de qualidade, eficiência e eficácia do sistema educativo.

Assim, o complemento teórico necessário das políticas de formação de professores, tanto em Portugal como no Brasil, "encontra-se no campo da teoria, na forja pragmática de um novo vocabulário processo também denominado criação de "novos desenhos conceituais" - que impõe uma ressignificação de conceitos, categorias, termos e sinais, de modo a torná-los condizentes com os emergentes paradigmas que referenciam a transformação almejada para a educação contemporânea. Competência, equidade, eficácia, eficiência, gestão, destreza, consenso, sociedade civil, democracia, cidadania, tolerância, edificação, professor, solidariedade, racionalidade,

\footnotetext{
${ }^{13}$ Cf. decreto-lei no $344 / 89$, de 11 de outubro.
} 
verdade, conhecimento, entre outros, são todos tragados pela retórica neopragmática em vigor e adquirem sentido e significado adequados aos novos tempos (Pacheco, Moraes \& Evangelista, 2001).

Por sua vez, a formação contínua de professores, cujo processo se institucionaliza a partir do momento em que a formação é considerada um pré-requisito para a progressão na carreira, a partir dos anos de $1990,{ }^{14}$ com publicação do ordenamento jurídico, é realizada ao nível das escolas dos ensinos básico e secundário, entretanto organizadas em centros de formação contínua, vincando a perspectiva administrativa, pois pretende à administração central não só a definição das regras de financiamento, bem como a delimitação das áreas prioritárias e das modalidades de formação.

A formação de formadores e de educadores é outro momento na consolidação do campo educacional. A dos primeiros, por imperativos da União Européia; a dos últimos, por afirmação das instituições de ensino superior e pelas necessidades sociais. A pósgraduação em educação surge nos anos 1980 em diversas universidades portuguesas e constitui, hoje em dia, um dos pilares fundamentais quer das faculdades de psicologia e educação de instituições públicas (Lisboa, Porto, Coimbra) ou de diversas instituições privadas, quer do Instituto de Educação e Psicologia da Universidade do Minho. Com efeito, e como sublinhámos anteriormente, as ciências da educação têm sido reconhecidas como domínio de conhecimento mais por aspectos institucionais, numa resposta à necessidade de formar educadores e professores, do que por uma lógica epistemológica, transformandose numa comunidade ainda relativamente frágil e estigmatizada pelo "eduquês" nos mídia.

\section{Os tempos investigativos no campo educacional}

Se a formação inicial, por um lado, está na origem da institucionalização do campo educacional, em

\footnotetext{
${ }^{14}$ Cf. decreto-lei no 249/92, de 9 de novembro.
}

Portugal, por outro, e sabendo-se que é um domínio reconhecidamente difícil a diversos títulos, constata-se que tem concitado "um escasso interesse por parte da recente comunidade dos investigadores das ciências da educação (apenas 7\% dos trabalhos produzidos nos anos 90 abordam o campo da formação inicial de professores)" (Rodrigues \& Esteves, 2003, p. 15).

Dilatando a pesquisa, a produção bibliográfica (livros, artigos, comunicações, dissertações de mestrado e doutoramento) sobre formação de professores ligada às questões curriculares representa somente $18 \%$ dos trabalhos realizados e publicados (Pacheco, 2002). Porém esta dificuldade não impede que seja estabelecida uma ligação muito estreita entre formação de professores e ciências da educação.

Percorrendo-se o século XX na procura de tempos investigativos para o campo educacional, identificam-se pelo menos dois momentos principais: a) 1901-1974: o momento da empirismo; b) 1975-1999: o momento da investigação.

O momento do empirismo representa a noção de que o campo educacional não necessita de formas complexas de investigação, pois as propostas estão na experiência imediata e concreta dos professores. E a experiência não precisa ser interpretada e sistematizada. Neste período, a investigação educativa está ausente ou então reconhece-se em estados incipientes de investigação experimental, sobretudo a partir da década de 1960, momento em que começa a ser publicada, na Universidade de Coimbra, a Revista Portuguesa de Pedagogia.

O momento da investigação inicia-se em $1975,{ }^{15}$ embora, na prática, só passados alguns anos se torne visível, com a formação inicial de professores, dentro do denominado modelo integrado, nas universida-

15 Também poderíamos propor como marco deste momento o ano de 1971, com o início do modelo sequencial ao nível das licenciaturas dos vários cursos de formação educacional, nas Faculdades de Ciências das Universidades de Lisboa e Porto e na Faculdade de Ciências e Tecnologia da Universidade de Coimbra, de acordo com o decreto-lei $n^{\circ}$ 443/71, de 11 de outubro. 
des portuguesas. Neste momento, podem ser identificados três ciclos: o ciclo da universitarização, o ciclo da administração e o ciclo institucional.

O ciclo da universitarização é o mais abrangente em termos de investigação, embora não seja o mais determinante em termos do seu conteúdo. É a investigação realizada por imperativos de carreira dos professores universitários - no estudo sobre a comunidade científica portuguesa verifica-se que a maior parte dos investigadores $(82,4 \%)$ se encontra nas universidades (Jesuíno, 1995b, p. 182) - ou por educadores, formadores e professores de outros níveis de ensino que realizam, no âmbito da pós-graduação, as suas teses. Folheando-se as principais revistas portuguesa de educação, verifica-se que os artigos são escritos por professores de instituições de ensino superior e que a sua grande maioria provém de dissertações de mestrado e doutoramento. A temática dos artigos é muito próxima dos temas das dissertações, sendo mais dispersas as temáticas dos livros publicados em Portugal no campo educacional.

De facto, o que se escreve em contexto académico não é coincidente com aquilo que é publicado. Estaremos perante uma questão de legitimação ou de deslegitimação do texto académico? Ou, dito por outras palavras, estaremos perante temáticas marcadas pelo ritmo da progressão na carreira ou pelas questões escolhidas pelos organizadores de congressos ou ainda pela administração central?

Apesar da tendência marcante da hierarquia académica, o ciclo da administração é o mais determinante em termos de conteúdo da investigação educativa, na medida em que as agendas dos investigadores são fixadas pela administração central, sobretudo a partir do grande ciclo de reformas iniciado em meados dos anos de 1980 e que ainda perdura. Os estrangulamentos existentes sobre a acção das ciências da educação devem-se ao peso da administração. Assim, “o controlo que o Ministério da Educação tem exercido nos últimos vinte anos é tão premente e tão asfixiante que não tem dado margem à intervenção das ciências da educação" (Estrela, 1999, p. 14).
Tal ciclo não pára de afirmar-se, levando os investigadores no campo educacional a escolher áreas declaradas prioritárias nos concursos para projectos de investigação e a ter uma agenda fortemente reactiva, ou seja, o conteúdo dos seus projectos obedecem a critérios mais de resposta a situações declaradas politicamente correctas. No mesma linha se situam alguns educadores críticos, cuja produção bibliográfica revela uma linguagem reactiva tão redundante como a linguagem de resistência e possibilidade (Pacheco, 2001).

Dentro do ciclo da administração existem dois subciclos: o ciclo da produção e disseminação da investigação politicamente controlada, mormente através de organizações da própria administração (por exemplo, o Gabinete de Estudos e Planeamento e o Instituto de Inovação Educacional); o ciclo da produção e disseminação da investigação organizacionalmente controlada, sobretudo quando a administração central contratualiza com académicos estudos devidamente orientados, de forma que sustente e valide, quase sempre a posteriori, as políticas educativas.

Ainda dentro do ciclo da administração, a investigação educativa é confrontada com um cultura de governação sui generis, em que o político-educador actua normativamente e conceptualiza a mudança. Para além dos enunciados teóricos, o político, administrador e académico ao mesmo tempo entra em processos e práticas de investigação marcados pelos escritos que reforçam o poder da administração. Donde que:

[...] paradoxalmente, vem-se assistindo ao longo dos últimos anos a uma crescente miscigenação, quando não mesmo a uma relativa inversão, tornando-se cada vez mais significativa a presença do discurso científico e das respectivas marcas teóricas e conceptuais na produção e circulação de discursos políticos e normativos, especialmente em textos legislativos, de regulamentação e de outros de tipo injuntivo, ao passo que a sua discussão pública e sobretudo a sua observação e análise em termos académicos parece, pelo contrário, conceder maior protagonismo à ideologização e ao debate político normativo, predominantemente orientando por categorias político-ideológicas mais típicas 
da acção política e dos seus confrontos. (Lima \& Afonso, 2002, p. 9)

Como sair deste círculo administrativo "em que nos fecharam, por que não dizê-lo, em que deixámos que nos fechassem?" (Estrela, 1999, p. 15).

A interrogação de Albano Estrela tem como resposta a criação de institutos:

[...] constituir, nas universidades que possuam os recursos adequados, grandes institutos de Educação, em que a planificação, a gestão, avaliação, a educação comparada, o desenvolvimento curricular e a formação ocupem o lugar a que têm direito, enquanto diferentes valências existentes nas várias unidades universitárias, dotados dos meios necessários a um exercício pleno de uma autonomia científica, pedagógica, administrativa e financeira. (idem)

A interrogação tem ainda como resposta a criação de centros de investigação educativa que funcionem não como meros organismos de gestão de recursos financeiros, em que o investigador é compensado pelo que escreve, mas como centros de excelência académica capazes de congregar investigadores pertencentes quer a diferentes departamentos, na busca da interdisciplinaridade, e áreas do conhecimento, quer a diferentes instituições.

O ciclo institucional corresponde à existência de projectos de investigação financiados, geralmente através de concurso, por organismos desconcentrados do Estado, com referência especial para a Fundação Ciência e Tecnologia, e por organismos tão diversos como Associações Profissionais e a Fundação Calouste Gulbenkian.

A Fundação para a Ciência e Tecnologia tem apoiado a investigação educativa por intermédio de Bolsas de Formação Avançada, Projectos de Investigação e Desenvolvimento e Unidades de Investigação e Desenvolvimento (registradas em 2001 pelo menos 10). ${ }^{16}$ A Fundação Calouste Gulbenkian, para além do

\footnotetext{
${ }^{16}$ Cf. <www.fct.mcs.pt/unidades2001>.
}

financiamento de Bolsas de Investigação, geralmente inseridas em projectos conducentes a graus (mestre e doutor), mantém um concurso anual de projectos aberto a toda a comunidade educativa.

A intersecção dos três ciclos de investigação fazse no momento em que os investigadores apresentam publicamente os seus resultados. Dentre as diversas possibilidades, registramos os palcos dos congressos realizados pela Sociedade Portuguesa de Ciências da Educação, a partir dos volumes de actas já publicados.

Nos cinco primeiros congressos que constituem o corpus de análise, regista-se que as temáticas dominantes dizem respeito (Tabela 1), por ordem decrescente, aos saberes, formação de professores/profissional, culturas, multiculturalismo e investigação:

Tabela 1 - Temáticas dominantes na investigação educativa

\begin{tabular}{lcc}
\hline \multicolumn{1}{c}{ Categorias } & $\begin{array}{c}\text { Unidades de } \\
\text { enumeração }\end{array}$ & $\%$ \\
\hline Saberes & 88 & 21,83 \\
Formação professores/profissional & 79 & 19,60 \\
Aprendizagens & 52 & 12,90 \\
Cultura(s) & 30 & 7,44 \\
Investigação & 28 & 6,94 \\
Diferenciação/igualdade & 21 & 5,21 \\
Inovação & 20 & 4,96 \\
Reforma & 19 & 4,72 \\
Cidadania/democracia & 19 & 4,72 \\
Avaliação & 17 & 4,22 \\
Qualidade & 15 & 3,73 \\
Multiculturalismo & 9 & 2,24 \\
Valores & 6 & 1,49 \\
\hline Total & 403 & 100
\end{tabular}

Em termos de metodologia, não existe ainda o predomínio do quantitativo ou do qualitativo, embora se verifique, nos últimos anos, a tendência para a investigação qualitativa. Intersectando tais resultados com os ciclos identificados, a quase totalidade dos trabalhos inclui-se nos ciclos da universitarização e administrativo, reconhecendo-se que este último é mais determinante em termos de conteúdo, enclau- 
surando os investigadores em percursos previamente definidos. Neste caso, menos dialogante fica a comunidade de investigação, pois as suas relações interdisciplinares, no esforço de rasgar fronteiras, são muito débeis.

\section{Conclusão}

Por mais que se escreva sobre os tempos e lugares do campo educacional, no esforço de analisar ao longo do século XX os percursos de investigação em Portugal, reconhecer-se-á que estamos numa fase de crescimento em direcção à sua consolidação. O que se passa no campo educacional precisa de ser cruzado com a especificidade da comunidade científica, por mais redes de colaboração que existam internacionalmente.

Assim,

[...] em termos globais, a comunidade científica portuguesa apresenta um conjunto de indicadores que reflectem a posição periférica ou semiperiférica do país quando comparado com os seus congéneres ocidentais. Portugal é um país pequeno, apenas com 10 milhões de habitantes, e com recursos reduzidos, o que necessariamente afecta a dimensão e qualidade da sua actividade científica. (Jesuíno, 1995b, p. 181)

Além do aspecto periférico, há mais dois aspectos que podem ser referidos: a universitarização e o tempo dedicado à investigação. Se a investigação nos diferentes campos disciplinares é realizada, na sua maioria, nas universidades, a investigação educativa reforça ainda mais essa tendência, uma vez que os diferentes ciclos identificados são, na sua totalidade, realizados por académicos, ou por outros docentes que frequentam programas de pós-graduação nas universidades.

O investigador português, geralmente doutorado e docente do ensino superior, independentemente do campo disciplinar a que pertence, consagra mais tempo ao serviço docente, às tarefas administrativas e aos cargos de gestão e administração do que à in- vestigação. Neste sentido, o campo educacional confronta-se ainda mais com a realidade do docente/ administrador/investigador, o que contribui para o seu enfraquecimento e ainda para a pobreza do material científico publicado." ${ }^{17}$

Outra questão pertinente, em função dos tempos e lugares, é a difícil conjugação do vocábulo "ciências da educação" no seio das outras comunidades científicas, sobretudo as que fazem parte de projectos de formação de educadores e professores. Mesmo no interior da comunidade, o estudo do fenómeno educativo dilui-se na margem estreita de campos disciplinares, ora marcantes, ora subsidiários. Psicologia, sociologia, filosofia, história, ciência política são algumas das disciplinas mais procuradas para legitimar o campo educativo. E nesta procura de significação própria as ciências da educação ficam enredadas numa agenda investigativa politicamente activa, cujo epicentro se localiza mais no exterior, com ênfase na escola e na formação, e menos no interior de uma comunidade que não se tem organizado no sentido de construir uma outra imagem, cada vez mais necessária.

JOSÉ AUGUSTO BRITO PACHECO, doutor pela Universidade do Minho (Braga, Portugal), é professor associado com agregação, nessa mesma universidade, na qual é responsável pela coordenação da área de desenvolvimento curricular e membro do Conselho Científico do Instituto de Educação e Psicologia. Publicou recentemente: Políticas curriculares; referenciais para análise (Porto Alegre: Artes Médicas, 2003); Políticas educativas; o neoliberalismo em educação (Porto: Porto Editora, 2001) e organizou Políticas de integração curricular (Porto: Porto Editora, 2000). Coordena os seguintes projetos de pesquisa: Avaliação de programas de formação profissional; um estudo de caso, com a Universidade de Sevilha, no âmbito do Curso de Organização e Avaliação da Formação; Teoria e prática da construção curricular, no Centro de Estudos em Educação e Psicologia, da Universidade

${ }^{17}$ Trata-se de uma constatação de António Nóvoa (2001), quando diz que as ciências da educação estão muito aquém do que seria desejável. 
do Minho; e Avaliação de projectos de inovação educativa, financiado pelo Programa Luso-Espanhol e Conselho de Reitores das Universidades Portuguesas. E-mail: jpacheco@iep. uminho.pt

\section{Referências bibliográficas}

ABRAGMAN, Anatole, (1988). Teoria ou experiência: um debate arcaico. In: HAMBURGER, J. (coord.). A filosofia das ciências hoje. Lisboa: Fragmentos, p. 25-36.

BALL, Stephen, (1995). Intellectuals or technicians? The urgent role of theory in educational studies. British Journal of Educational Studies, $\mathrm{n}^{\circ} 33$, p. 255-271.

BEAUCHAMP, George, (1961). Curriculum theory. Wilmette: The Kagg Press.

BUNGE, Mario, (1980). Epistemologia. Curso de atualização. São Paulo: Editora da Universidade de São Paulo.

CARR, Wilfred, (1985). Philosophy, values and educational science. Journal of Curriculum Studies, v. 17, n 2, p. 119-132.

CARR, Wilfred, KEMMIS, Stephen, (1988). Teoría crítica de la enseñanza. Barcelona: Martínez Roca.

CHERRYHOLMES, Cleo, (1993). Um projecto social para o currículo: perspectivas pós-estruturais. In: SILVA, T. Tadeu da (org.). Teoria educacional crítica e tempos pós-modernos. Porto Alegre: Artes Médicas, p. 143-172.

COMISSÃO GULBENKIAN, (1996). Para abrir as ciências sociais. Lisboa: Presença.

DASCAL, Marcelo, (1999). A polémica na ciência. In: GIL, F. (org.). A ciência tal qual se faz. Lisboa: Edições João Sá da Costa, p. 65-77.

DELATTRE, P. , (1992). Teoria/Modelo. In: ROMANO, R. (dir.). Enciclopédia Enaudi - v. 21. Lisboa: Imprensa Nacional Casa da Moeda, p. 223-287.

ESTEVES, Manuela, (2002). A investigação enquanto estratégia de formação de professores. Lisboa: Instituto de Inovação Educacional.

ESTRELA, Albano (1992). Pedagogia, ciência da educação? Porto: Porto Editora. , (1999). O tempo e o lugar das ciências da educação. Porto: S.P. C.E. / Porto Editora.

FORMOSINHO, Sebastião, (1988). Nos bastidores da ciência. Lisboa: Gradiva.

GIDDENS, Anthony, (1996). As consequências da modernidade. $3^{\text {a }}$ ed. Oeiras: Celta.
GIMENO, José, (1998). Poderes inestables en educación. Madrid: Morata.

HAMBURGER, Jean, (coord.) (1988). A filosofia das ciências hoje. Lisboa: Fragmentos.

JESUÍNO, Jorge, (1995a). Introdução. In: JESUÍNO, J. (coord.). A comunidade científica portuguesa nos finais do século $X X$. Oeiras: Celta, p. 1-10.

, (1995b). Conclusão. In: JESUÍNO, J. (coord.). A comunidade científica portuguesa nos finais do século $X X$. Oeiras: Celta, p. 181-185.

LERBERT, George, (1996). Les nouvelles sciences de l'éducation. Paris: Nathan.

LIMA, Licínio, AFONSO, Almerindo, (2002). Reformas da educação pública. Democratização, modernização, neoliberalismo. Porto: Afrontamento.

MACDONALD, James, (1995). Theory, practice and the hermeneutic circle. In: MACDONALD, J. (ed.). Theory as a prayerful act. New York: Peter Lang, p. 173-186.

MOLES, Abraham, (1981). A criação científica. São Paulo: Perspectiva.

NÓVOA, António, (2001). Eu pedagogo, me confesso. Diálogos com Rui Grácio. Inovação, v. 14, nº 1-2, p. 9-33.

PACHECO, José, (1995). Formação de professores: teoria e práxis. Braga: Universidade do Minho.

, (2001). Teoria curricular crítica: as contradições (e dilemas) dos educadores críticos. Revista Portuguesa de Educação, v. 13, n.3, p. 49-71.

, (2002). Notas para uma síntese de uma década de consolidação dos estudos curriculares. Investigar em Educação, v. 1, p, 227-273.

, (2003). Políticas curriculares. Referenciais para análise. Porto Alegre: Artes Médicas.

PACHECO, José, MORAES, M. Célia, EVANGELISTA, Olinda, (2001).

Políticas educacionais nos anos 90: a formação de professores no Brasil e em Portugal. Educar em Revista, n 18, p. 185-200.

PRIGOGINE, Ilya, (1996). La fin des certitudes. Temps, chaos et les lois de la nature. Paris: Odile Jacob.

RODRIGUES, Ângela, ESTEVES, Manuela, (2003). Tornar-se professor. Investigar em Educação, no 2, p. 15-68.

SANTOS, Boaventura de Souza, (1993). Introdução a uma ciência pós-moderna. $3^{\mathrm{a}}$ ed. Porto: Afrontamento.

SILVA, Tomaz Tadeu da, (2000). Teorias curriculares. Uma introdução crítica. Porto: Porto Editora. 
THOMAS, Gary, (1997). What's the use of theory? Harvard Educacional Review, v. 67, n 1, p. 75-104.

VALA, Jorge, AMÂNCIO, Lígia, (1995). A comunidade científica portuguesa nos finais do século XX: comportamentos, atitudes e expectativas. In: JESUÍNO, J. (coord.). A comunidade científica portuguesa nos finais do século XX. Oeiras: Celta, p. $89-106$.

WEBER, Max, (1977). Sobre a teoria das ciências sociais. Lisboa: Presença.
WULF, Christof, (1995). Introduction aux sciences de l'éducation. Paris: Armand Colin.

ZABALZA, Miguel, (1992). Fundamentación de la didáctica y del conocimiento didáctico. In: MEDINA, A., SEVILLANO, M. (coords.). Didáctica - adaptación. El curriculum: fundamentación, diseño, desarrollo y evaluación. Madrid: UNED, p. $88-120$.

Recebido em setembro de 2003 Aprovado em dezembro de 2003 